\title{
Stroke and digital technology: a wake-up call from COVID-19 pandemic
}

\author{
Francesco lodice ${ }^{1,2,3}$ (D) Michele Romoli $^{4,5} \cdot$ Bruno Giometto $^{6}$ - Marinella Clerico ${ }^{7}$. Gioacchino Tedeschi ${ }^{8}$.

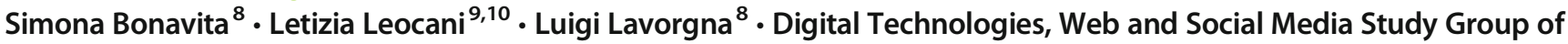 \\ the Italian Society of Neurology
}

Received: 14 October 2020 / Accepted: 11 December 2020 / Published online: 12 January 2021

(C) Fondazione Società Italiana di Neurologia 2021

\begin{abstract}
Introduction The pandemic has implemented the need for new digital technologies as useful tools during the emergency and the long recovery phase that will follow. SARS-CoV-2 has strongly impacted stroke care with significant contraction in a number of patients treated.

Methods This mini-review is an initiative of the "Digital Technologies, Web and Social Media Study Group" of the Italian Society of Neurology and briefly discusses digital tools for managing the acute phase and the rehabilitation after stroke, even considering the new apps that will improve the process of remote monitoring of patients after discharge at home.

Results Telemedicine and digital technologies could play a role in each of the three stroke-belt stages: hyperacute treatment and reperfusion, acute care, etiological classification and secondary prevention and rehabilitation.

Conclusion The global emergency represented by the COVID-19 pandemic can be the stimulus to accelerate the digitalization process in the field of stroke for the use of new methods on a large scale.
\end{abstract}

Keywords Stroke $\cdot$ Telemedicine $\cdot$ Telerehabilitation $\cdot$ Teleneurology $\cdot$ Telehealth $\cdot$ COVID-19

The novel coronavirus-2 (SARS-Cov-2) has spread from China all over the world, and the national health systems had to cope with primary and secondary effects of the SARS-Cov-2 disease (COVID-19). The world of neurology has not been immune to the virus either [1-3], and beyond its primary impact on the population, secondary consequences of the pandemic emerged for time-dependent diseases, including

Francesco Iodice and Michele Romoli contributed equally to this work.

Francesco Iodice

franc.iodice@gmail.com

1 Institute of Neurology, Fondazione Policlinico Gemelli, IRCCS, Rome, Italy

2 Department of Neuroscience and Neurorehabilitation, San Raffaele Pisana IRCCS, Rome, Italy

3 Digital Technologies, Web and Social Media Study Group of the Italian Society of Neurology Francesco Iodice (Member), Largo A. Gemelli 8, 00168 Rome, Italy

4 Department of Neurology and Metropolitan Stroke Center, IRCCS Istituto delle Scienze Neurologiche di Bologna, "C.A. Pizzardi" Maggiore Hospital, Bologna, Italy stroke. The extension of reperfusion window and the broughton-stage of thrombectomy exponentially increased stroke care treatments until late 2019 [4]. Starting from the earliest stages of the emergency, the risk of underestimating and undertreating many cases of stroke that could have benefited from treatment was recognized and it generated an appeal not to stay at home if acute neurological symptoms appeared [5].

5 Neurology Clinic, University of Perugia, Perugia, Italy

6 Department of Neurology, "Santa Chiara" Hospital APSS, Trento, Italy

7 Department of Clinical and Biological Sciences, University of Turin, Orbassano, Italy

8 Department of Advanced Medical and Surgical Sciences, University of Campania "Luigi Vanvitelli", Naples, Italy

9 Department of Neurorehabilitation and INSPE-Institute of Experimental Neurology, IRCCS San Raffaele Hospital and University Vita-Salute, Milan, Italy

10 University Vita-Salute San Raffaele, Milan, Italy 
However, in the first period of the pandemic, we assisted to a $50 \%$ reduction in admissions to the emergency department (ED) or stroke units for acute ischemic stroke, according to data from 81 stroke units in Italy reported by the Italian Stroke Organization and similar rates were seen in France [6]. A 50\% reduction in a number of thrombectomies has also been reported in Shanghai in the first month of the pandemic [7], pointing to a plausible consequence of the pandemic on stroke time-dependent pathway. In the 2-week timeframe that included the end of March and the beginning of April 2020, compared with the same period of the previous year, the analysis of total acute treatments for stroke in the over 850 hospitals in the USA using the RAPID software, showed a decrease of $39 \%$ [8]. Similar admission trends were observed in the UK where there was also an increase in the average severity of cases arriving in hospital [9]. An analysis of data in a secondary phase of the pandemic in tertiary care unit in Italy showed that the most serious strokes had hospital access rates comparable to previous years and the contraction was mainly in the milder forms [10]. Policies minimizing provider-patient interactions as well as personal reticence to come to the ED during the pandemic might have participated in such contraction, which has prompted international societies to speak up to maintain efficient stroke pathways. At the same time, the pandemic has fostered the use of telemedicine in the field of stroke, disclosing the potential of its implementation transversally, in all treatment stages $[11,12]$.

The COVID emergency, beyond its tragedy, has been so far an opportunity for a profound reflection on the theme of new digital technologies in the various neurological disciplines [13-17], and the greatest impact could be in the field of stroke. Even if the field of stroke is probably the one in which development of telehealth was greater among all the other neurological disciplines, with a path started several years ago, this pandemic may be a key moment for its large-scale use [18, 19].

The standard course of a subject affected by acute stroke could be divided in 3 phases: hospitalization in a facility for hyperacute and acute care, followed by an intensive rehabilitation phase in a hospital or day-hospital regime and the return home to daily activities with a periodic follow-up [20, 21]. The new telemedicine, gaming, and neurorobotic technologies can play a role in each of these three main phases that represent the medical response to a stroke. The main aim of stroke units and stroke network is to reduce mortality by providing acute patient monitoring, to avoid complications, such as aspiration pneumonia, venous thromboembolism, and pressure sores, and to start early rehabilitation and institute targeted secondary prevention $[22,23]$.

Consequences of stroke on lost motor functions, language skills, and cognitive deficits cause the inability of a subject to return to daily functions, require assistance from family members or dedicated caregivers, and have significant economic costs for the family and the health system. Implementation of telemedicine in stroke networks was proposed to guarantee standardized expertise in the management of patients and also in remote locations or in conditions with limited access to medical attention [24, 25].

Evidence supporting the equivalence of telestroke to inperson care accumulated over time, with similar rates of stroke mimics, superimposable stroke scale scores (including NIHSS), and, most importantly, with comparable good functional outcome after hyperacute treatment [24, 26-28]. Several remote communication tools have been developed to meet the demand of stroke workload on the basis of the shortage of vascular neurologists. Treatment decisions made through apps developed to share clinical and imaging data meant to facilitate and speed up stroke treatment have been shown to be as accurate as in-person evaluation [29]. Thrombectomy services are also evolving to robotic-assisted stage, with telerobotic systems potentially improving neurointervention itself $[30,31]$. Such treatment paradigms might become paramount under pandemic circumstances, allowing stroke pathways to proceed limiting the contact of health personnel and allowing for multiple procedures to happen in shorter time.

Digital technology is also entering the field of stroke etiology differentials. In a time where convolutional classifications are facing the need of extensive monitoring [32], and stroke resources are reduced to the essential to leave way to the care of COVID-19, atrial fibrillation (AF) cannot be missed. The diagnosis of $\mathrm{AF}$ is crucial to prevent cardioembolic stroke, and therefore paramount to control the burden of recurrent stroke and cerebrovascular disease. Screening for both symptomatic and asymptomatic AF has been demonstrated effective with mechanocardiography, using recordings of mechanical cardiac activity through accelerometers and gyroscopes in smartphones [33]. Photoplethysmography with a smartphone camera has been demonstrated as effective as internet-enabled electrocardiography for AF screening [34]. Automatic realtime detection of AF in non-invasive ECG signals, counting on beat to beat variability, tachogram analysis, and simple signal filtering, has been demonstrated feasible with mobile devices [35], while proper apps built to record a rhythm strip using smartwatches have been shown accurate in differentiating AF from sinus rhythm [36]. Recently, the Apple Heart Study [37] demonstrated the availability of an app for detecting AF in subject without a previous history of this arrhythmia. In over 400,000 participants, notifications for irregular cardiac pulse were sent in $0.52 \%$ of the study population and, among them, AF was detected with the ECG in $34 \%$ of the cases, thus providing a first evidence for the use of telephone apps in this field.

Telemedicine has critical weight in rehabilitation [38]. Several data from scientific literature have shown that brain 
plasticity phase after stroke does not end in the first few months and can continue a long time after the acute event if the learning program does not stop [39, 40]. Given the drastic reduction in the offer of rehab services during the pandemic, due to the conversion of facilities to host COVID-19 patients, digital technology can represent a key tool in this phase. On the Google trend engine, searches for the term "telerehab" grew by about $400 \%$ in the first week of March 2020 and have reached unprecedented values.

Depending on the availability of the user, the telerehab sessions can be performed by phone, via videoconferencing software or through dedicated apps (i.e., "REHABmyPatient," "myRehab," or "RehabPal").

In conclusion, telemedicine will be included among the major historical changes that the COVID-19 pandemic will bring to clinical practice due to its ability to take care of people, minimizing the use of protective devices and making medical practice safer for operators. Digital technology has consistently been implemented in stroke care in the last few years, as the acute and chronic management of cerebrovascular disease is particularly suitable for telemedicine, especially during the COVID-19 pandemic. The COVID emergency, beyond its tragedy, has been so far an opportunity for a profound reflection on the theme of new digital technologies in the various neurological disciplines [13-17], and the greatest impact could be in the field of stroke.

Acute care can benefit from telemedicine paradigms to guide drip-and-ship models and provide high standards of care even in remote areas. The etiological classification of stroke counts on extensive search of AF, which can nowadays be pursued through dedicated apps and teledetection systems. Finally, efforts should be directed to the implementation of telerehabilitation, which has been demonstrated to provide an extensive benefit for stroke recovery, especially for cortical symptoms and dexterity. During the COVID-19 pandemic, telerehabilitation can be critically useful to limit in-person consultation and provide a tele-hotpursuit, making optimal secondary prevention and rehabilitation feasible even in lockdown times.

\footnotetext{
Acknowledgements Giovanni Mancardi, Department of Neuroscience, Rehabilitation, Ophthalmology, Genetics, Maternal and Child Health, University of Genova; Alessandro Padovani, Neurology Unit, Department of Clinical and Experimental Sciences, University of Brescia; Francesco Brigo, Department of Neurology, Franz Tappeiner Hospital, Merano; Eleonora Cocco, Department of Medical Sciences and Public Health, University of Cagliari; Roberta Lanzillo, Department of Neuroscience, Reproductive Science and Odontostomatology, Federico II University of Naples; Antonio Russo, Department of Advanced Medical and Surgical Sciences, University of Campania "Luigi Vanvitelli," Naples; Giulia Straccia, Department of Advanced Medical and Surgical Sciences, University of Campania "Luigi Vanvitelli," Naples; Rosa Iodice, Department of Neuroscience, Reproductive Science and Odontostomatology, Federico II University of Naples; Sebastiano Bucello, Department of Neurology, Azienda Ospedaliera Asp 8 Siracusa, C.da Granatello, Augusta; Pietro
}

Annovazzi, Department of Neurology, Gallarate Hospital, Milano; Marcello Moccia, Department of Neuroscience, Reproductive Science and Odontostomatology, Federico II University of Naples; Luca Prosperini, Department of Neurosciences, Ospedale San Camillo Forlanini, Rome; Maria Laura Stromillo, Department of Medicine, Surgery and Neuroscience, University of Siena; Anna Maria Repice, Department of Neurology, AOU Careggi, Firenze; Giuseppina Miele, Department of Advanced Medical and Surgical Sciences, II Clinic of Neurology, University of Campania “Luigi Vanvitelli," Naples; Alberto Lerario, Policlinico Hospital of Milan; Antonio De Martino, Institute of Neurology, University of Catanzaro; Francesco Di Lorenzo, Non Invasive Brain Stimulation Unit, IRCSS Fondazione Santa Lucia, Rome; Alessandro Bombaci, "Rita Levi Montalcini" Department of Neuroscience, University of Torino, Turin, Italy, Luca Cuffaro, Department of Biomedicine, Neuroscience and Advanced Diagnostic, University Hospital "Paolo Giaccone," Palermo; Gianmarco Abbadessa, Department of Advanced Medical and Surgical Sciences, II Clinic of Neurology, University of Campania "Luigi Vanvitelli," Naples, Italy; Francesca Trojsi, Department of Advanced Medical and Surgical Sciences, I Clinic of Neurology, University of Campania "Luigi Vanvitelli," Naples, Italy; Marcello Silvestro, Department of Advanced Medical and Surgical Sciences, University of Campania "Luigi Vanvitelli," Naples; Carlo Alberto Artusi, Department of Neuroscience "Rita Levi Montalcini," University of Torino.

Authors' contribution Francesco Iodice and Michele Romoli equally contributed to the conception of the study, literature revision, and manuscript drafting; Bruno Giometto and Marinella Clerico contributed to the conception of the study and revised the article and table for intellectual content; Luigi Lavorgna, Gioacchino Tedeschi, and Simona Bonavita contributed to the conception of the study and final revision of the article. All authors equally contributed to the final approval of the version to be submitted.

\section{Compliance with ethical standards}

Conflict of interest The authors declare that they have no conflict of interest.

Ethical approval This work falls under the remit of quality improvement during COVID-19 emergency and ethical approval was not requested.

Research involving human participants and/or animals No human participants or animals were involved in this research.

Informed consent This work falls under the remit of quality improvement during COVID-19 emergency and ethical approval was not requested.

\section{References}

1. Mao L, Jin H, Wang M, Hu Y, Chen S, He Q, Chang J, Hong C, Zhou Y, Wang D, Miao X, Li Y, Hu B (2020) Neurologic manifestations of hospitalized patients with coronavirus disease 2019 in Wuhan, China. JAMA Neurol 77:683-690. https://doi.org/10. 1001/jamaneurol.2020.1127

2. Gao J, Zheng P, Jia Y, Chen H, Mao Y, Chen S, Wang Y, Fu H, Dai J (2020) Mental health problems and social media exposure during COVID-19 outbreak. PLoS One 15:e231924. https://doi.org/10. 1371/journal.pone.0231924

3. Federico A (2020) Experiencing COVID19 pandemic and neurology: learning by the recent reports and by old literary or scientific 
descriptions. Neurol Sci 41:1-5. https://doi.org/10.1007/s10072020-04471-w

4. Gill D, Lobo R, Sivakumaran P, Kar A (2016) Expected thrombectomy caseload. Int J Stroke 11:NP76-NP76. https://doi. org/10.1177/1747493016641115

5. Baracchini C, Pieroni A, Viaro F, Cianci V, Cattelan AM, Tiberio I, Munari M, Causin F (2020) Acute stroke management pathway during Coronavirus-19 pandemic. Neurol Sci 41:1003-1005. https://doi.org/10.1007/s10072-020-04375-9

6. Bersano A, Kraemer M, Touzé E, Weber R, Alamowitch S, Sibon I, Pantoni L (2020) Stroke care during the COVID-19 pandemic: experience from three large European countries. Eur J Neurol 27: 1794-1800. https://doi.org/10.1111/ene.14375

7. Zhao J, Rudd A, Liu R (2020) Challenges and potential solutions of stroke care during the coronavirus disease 2019 (COVID-19) outbreak. Stroke 364:2019-2020. https://doi.org/10.1161/ STROKEAHA. 120.029701

8. Kansagra AP, Goyal MS, Hamilton S, Albers GW (2020) Collateral effect of Covid-19 on stroke evaluation in the United States. N Engl J Med 383:400-401. https://doi.org/10.1056/NEJMc2014816

9. Padmanabhan N, Natarajan I, Gunston R, Raseta M, Roffe C (2020) Impact of COVID-19 on stroke admissions, treatments, and outcomes at a comprehensive stroke centre in the United Kingdom. Neurol Sci. https://doi.org/10.1007/s10072-020-04775$\mathrm{x}$

10. Zini A, Romoli M, Gentile M, Migliaccio L, Picoco C, Dell'Arciprete O, Simonetti L, Naldi F, Piccolo L, Gordini G, Tagliatela F, Bua V, Cirillo L, Princiotta C, Coniglio C, Descovich C, Cortelli P (2020) The stroke mothership model survived during COVID-19 era: an observational single-center study in Emilia-Romagna. Italy Neurol Sci 41:3395-3399. https://doi. org/10.1007/s10072-020-04754-2

11. Lin JC, Humphries MD, Shutze WP, Aalami OO, Fischer UM, Hodgson KJ (2020) Telemedicine platforms and their use in the coronavirus disease-19 era to deliver comprehensive vascular care. J Vasc Surg. https://doi.org/10.1016/j.jvs.2020.06.051

12. Ting DSW, Carin L, Dzau V, Wong TY (2020) Digital technology and COVID-19. Nat Med 26:459-461. https://doi.org/10.1038/ s41591-020-0824-5

13. Cuffaro L, Di Lorenzo F, Bonavita S et al (2020) Dementia care and COVID-19 pandemic: a necessary digital revolution. Neurol Sci 41: 1977-1979. https://doi.org/10.1007/s10072-020-04512-4

14. Moccia M, Lanzillo R, Brescia Morra V et al (2020) Assessing disability and relapses in multiple sclerosis on tele-neurology. Neurological Sciences: Official Journal of the Italian Neurological Society and of the Italian Society of Clinical Neurophysiology 41: 1369-1371. https://doi.org/10.1007/s10072-020-04470-x

15. Miele G, Straccia G, Moccia M, Leocani L, Tedeschi G, Bonavita S, Lavorgna L, on behalf of the Digital Technologies, Web and Social Media Study Group of the Italian Society of Neurology, Padovani A, Clerico M, Brigo F, Cocco E, Lanzillo R, Russo A, Giometto B, Trojsi F, Iodice R, Bucello S, Annovazzi P, Prosperini L, Stromillo ML, Repice AM, Abbadessa G, Lerario A, DeMartino A, Bombaci A, Iodice F, di Lorenzo F, Cuffaro L, Romoli M, Silvestro M, Alberto Artusi C (2020) Telemedicine in Parkinson's disease: how to ensure patient needs and continuity of care at the time of COVID-19 pandemic. Telemedicine Journal and E-Health: The Official Journal of the American Telemedicine Association 26: 1533-1536. https://doi.org/10.1089/tmj.2020.0184

16. Brigo F, Bonavita S, Leocani L, Tedeschi G, Lavorgna L, Digital Technologies, Web and Social Media Study Group of the Italian Society of Neurology (2020) Telemedicine and the challenge of epilepsy management at the time of COVID-19 pandemic. Epilepsy \& Behavior: E\&B 110:107164. https://doi.org/10.1016/j. yebeh.2020.107164
17. Bonavita S, Tedeschi G, Atreja A, Lavorgna L (2020) Digital triage for people with multiple sclerosis in the age of COVID-19 pandemic. Neurol Sci 41:1007-1009. https://doi.org/10.1007/s10072-02004391-9

18. Markus HS, Brainin M (2020) COVID-19 and stroke-a global World Stroke Organization perspective. International Journal of Stroke: Official Journal of the International Stroke Society 15: 361-364. https://doi.org/10.1177/1747493020923472

19. Leira EC, Russman AN, Biller J, Brown DL, Bushnell CD, Caso V, Chamorro A, Creutzfeldt CJ, Cruz-Flores S, Elkind MSV, Fayad P, Froehler MT, Goldstein LB, Gonzales NR, Kaskie B, Khatri P, Livesay S, Liebeskind DS, Majersik JJ, Moheet AM, Romano JG, Sanossian N, Sansing LH, Silver B, Simpkins AN, Smith W, Tirschwell DL, Wang DZ, Yavagal DR, Worrall BB (2020) Preserving stroke care during the COVID-19 pandemic: potential issues and solutions. Neurology 95:124-133. https://doi.org/10. 1212/WNL.0000000000009713

20. Winstein CJ, Stein J, Arena R, Bates B, Cherney LR, Cramer SC, Deruyter F, Eng JJ, Fisher B, Harvey RL, Lang CE, MacKay-Lyons M, Ottenbacher KJ, Pugh S, Reeves MJ, Richards LG, Stiers W, Zorowitz RD, American Heart Association Stroke Council, Council on Cardiovascular and Stroke Nursing, Council on Clinical Cardiology, and Council on Quality of Care and Outcomes Research (2016) Guidelines for adult stroke rehabilitation and recovery: a guideline for healthcare professionals from the American Heart Association/American Stroke Association. Stroke 47:e98 e169. https://doi.org/10.1161/STR.0000000000000098

21. Powers WJ, Rabinstein AA, Teri A et al (2019) Guidelines for the early management of patients with acute ischemic stroke: 2019 update to the 2018 Guidelines for the Early Management of Acute Ischemic Stroke: a guideline for healthcare professionals from the American Heart Association/American Stroke Association. Stroke 50:e344-e418. https://doi.org/10.1161/STR.0000000000000211

22. Campbell BCV, Khatri P (2020) Stroke. Lancet 396:129-142. https://doi.org/10.1016/S0140-6736(20)31179-X

23. Millikan CH (1979) Stroke intensive care units: objectives and results. Stroke 10:235-237. https://doi.org/10.1161/01.str.10.3.235

24. Wechsler LR, Demaerschalk BM, Schwamm LH, Adeoye OM, Audebert HJ, Fanale CV, Hess DC, Majersik JJ, Nystrom KV, Reeves MJ, Rosamond WD, Switzer JA (2017) Telemedicine quality and outcomes in stroke: a scientific statement for healthcare professionals from the American Heart Association/American Stroke Association. Stroke 48:e3-e25. https://doi.org/10.1161/ STR.0000000000000114

25. Demaerschalk BM, Miley ML, Kiernan T-EJ et al (2009) Stroke telemedicine. Mayo Clin Proc 84:53-64

26. Hatcher-Martin JM, Adams JL, Anderson ER, Bove R, Burrus TM, Chehrenama M, Dolan O'Brien M, Eliashiv DS, Erten-Lyons D, Giesser BS, Moo LR, Narayanaswami P, Rossi MA, Soni M, Tariq N, Tsao JW, Vargas BB, Vota SA, Wessels SR, Planalp H, Govindarajan R (2020) Telemedicine in neurology: Telemedicine Work Group of the American Academy of Neurology update. Neurology 94:30-38. https://doi.org/10.1212/WNL. 0000000000008708

27. Wysocki NA, Bambhroliya A, Ankrom C, Vahidy F, Astudillo C, Trevino A, Malazarte R, Cossey TC, Jagolino-Cole A, Savitz S, Wu TC, Sharrief A (2019) Outcomes among patients with ischemic stroke treated with intravenous tPA (tissue-type plasminogen activator) via telemedicine: is the drip-and-stay model safe? Stroke 50:895-900. https://doi.org/10.1161/STROKEAHA.118. 024703

28. Gabriel KMA, Jírů-Hillmann S, Kraft P, Selig U, Rücker V, Mühler J, Dötter K, Keidel M, Soda H, Rascher A, Schneider R, Pfau M, Hoffmann R, Stenzel J, Benghebrid M, Goebel T, Doerck S, Kramer D, Haeusler KG, Volkmann J, Heuschmann PU, Fluri F (2020) Two years' experience of implementing a comprehensive 
telemedical stroke network comprising in mainly rural region: The Transregional Network for Stroke Intervention with Telemedicine (TRANSIT-Stroke). BMC Neurol 20:1-13. https://doi.org/10. 1186/s12883-020-01676-6

29. Martins SCO, Weiss G, Almeida AG, Brondani R, Carbonera LA, de Souza AC, Martins MCO, Nasi G, Nasi LA, Batista C, Sousa FB, Rockenbach MABC, Gonçalves FM, Vedolin LM, Nogueira RG (2020) Validation of a smartphone application in the evaluation and treatment of acute stroke in a comprehensive stroke center. Stroke 51:240-246. https://doi.org/10.1161/STROKEAHA.119. 026727

30. Crossley R, Liebig T, Holtmannspoetter M, Lindkvist J, Henn P, Lonn L, Gallagher AG (2019) Validation studies of virtual reality simulation performance metrics for mechanical thrombectomy in ischemic stroke. Journal of NeuroInterventional Surgery 11:775780. https://doi.org/10.1136/neurintsurg-2018-014510

31. Bechstein M, Buhk JH, Frölich AM, Broocks G, Hanning U, Erler M, Anđelković M, Debeljak D, Fiehler J, Goebell E (2019) Training and supervision of thrombectomy by remote live streaming support (RESS): randomized comparison using simulated stroke interventions. Clin Neuroradiol. https://doi.org/10.1007/ s00062-019-00870-5

32. Paciaroni M, Kamel H (2019) Do the results of RE-SPECT ESUS call for a revision of the embolic stroke of undetermined source definition? Stroke 50:1032-1033. https://doi.org/10.1161/ STROKEAHA.118.024160

33. Jaakkola J, Jaakkola S, Lahdenoja O, et al (2018) Mobile phone detection of atrial fibrillation with mechanocardiography: the MODE-AF study (Mobile Phone Detection of Atrial Fibrillation). Circulation CIRCULATIONAHA.117.032804. https://doi.org/10. 1161/CIRCULATIONAHA.117.032804

34. Brasier N, Raichle CJ, Dörr M, Becke A, Nohturfft V, Weber S, Bulacher F, Salomon L, Noah T, Birkemeyer R, Eckstein J (2019)
Detection of atrial fibrillation with a smartphone camera: first prospective, international, two-centre, clinical validation study (DETECT AF PRO). Europace 21:41-47. https://doi.org/10.1093/ europace/euy176

35. Kaiser S, Kirst M, Kunze C (2010) Automatic detection of atrial fibrillation for mobile devices. Communications in Computer and Information Science 52:258-270. https://doi.org/10.1007/978-3642-11721-3 20

36. Bumgarner JM, Lambert CT, Hussein AA, Cantillon DJ, Baranowski B, Wolski K, Lindsay BD, Wazni OM, Tarakji KG (2018) Smartwatch algorithm for automated detection of atrial fibrillation. J Am Coll Cardiol 71:2381-2388. https://doi.org/10. 1016/j.jacc.2018.03.003

37. Mv P, Kw M, H H, et al (2019) Large-scale assessment of a smartwatch to identify atrial fibrillation. In: The New England journal of medicine. https://pubmed.ncbi.nlm.nih.gov/31722151/. Accessed 2 Dec 2020

38. Peretti A, Amenta F, Tayebati SK, Nittari G, Mahdi SS (2017) Telerehabilitation: review of the state-of-the-art and areas of application. JMIR Rehabil Assist Technol 4:e7. https://doi.org/10.2196/ rehab.7511

39. Liepert J, Bauder H, Wolfgang HR et al (2000) Treatment-induced cortical reorganization after stroke in humans. Stroke 31:1210 1216. https://doi.org/10.1161/01.str.31.6.1210

40. Pascual-Leone A, Amedi A, Fregni F, Merabet LB (2005) The plastic human brain cortex. Annu Rev Neurosci 28:377-401. https://doi.org/10.1146/annurev.neuro.27.070203.144216

Publisher's note Springer Nature remains neutral with regard to jurisdictional claims in published maps and institutional affiliations. 